\title{
Hepatic resection in children: highlighted and revisited steps
}

\author{
Hesham Mohammed Abdelkader ${ }^{1}$, Mohamed Abdel-Latif ${ }^{2}$, Mohamed Abdelsattar ${ }^{1}$ and \\ Ahmed Abdelhaseeb Youssef ${ }^{*}$
}

\begin{abstract}
Background: Hepatectomy in children deserves exhaustive preoperative and intraoperative tools to define the anatomy, minimize blood loss, and confirm adequacy of liver tissue left. The aim of this study is to report our experience in surgical management of liver tumors.
\end{abstract}

Results: All liver resections performed in Ain-Shams University Hospital, by the same team, between July 2013 and June 2018 were retrospectively reviewed. Data related to basic demographics, indication for resection, methods of parenchymal resection, blood loss, hospital stay, morbidity, and mortality was collected. The study included 27 patients who underwent different types of hepatectomies. There was a male predominance. Age ranged from 6 months to 13 years. Weight ranged from 5.7 to $33.7 \mathrm{~kg}$. Total operative time ranged from 68 to $322 \mathrm{~min}$, while resection time ranged from 34 to $144 \mathrm{~min}$. Blood loss ranged from 53 to $259 \mathrm{ml}$. Surgical morbidities included five patients with minor biliary leak, three patients had surgical site infection, and one patient had torsion of the remnant liver necessitating repositioning. Recurrence of the mass was faced in three patients with hepatoblastoma. There were two mortalities; one occurred as a sequela of massive intraoperative bleeding and the other took place due to postoperative hepatic insufficiency.

Conclusion: For a safe hepatectomy, thorough familiarity of the hepatic segmental anatomy together with the various techniques for parenchymal resection and vascular control is fundamental. Complications such as biliary leak and torsion of remnant can be easily avoided by simple measures.

Keywords: Liver resection, Hepatectomy, Liver neoplasm, Liver tumors

\section{Background}

Liver tumors are the third most common solid abdominal organ tumor in children representing $0.5-2 \%$ of pediatric neoplasm [1]. About half hepatic neoplasms are malignant with hepatoblastoma being the most common followed by hepatocellular carcinoma (HCC) [2]. Hemangioendothelioma, mesenchymal hamartoma, and focal nodular hyperplasia represent the vast majority of benign lesions [3]. Hepatectomies represent one of the most challenging procedures, so it deserves exhaustive preoperative and intraoperative tools to define the anatomy, minimize blood loss, and confirm the adequacy of liver tissue left [4]. These tools include computed tomography (CT)

\footnotetext{
* Correspondence: ahmedhaseb@gmail.com

${ }^{1}$ Pediatric Surgery Department, Ain-Shams University, Abbaseya, Cairo, Egypt Full list of author information is available at the end of the article
}

volumetry of the liver, intraoperative ultrasonography, cell saver, and ultrasonic scalpel [5].

The aim of this study is to report our experience in surgical management of liver tumors and highlighting beneficial techniques and gadgets.

\section{Methods}

All liver resections performed in Ain-Shams University Hospital, by the same team with more than 10 years' experience in hepatectomy and liver transplantation, between July 2013 and June 2018 were retrospectively reviewed. Data related to basic demographics, indication for resection, methods of parenchymal resection, blood loss, hospital stay, morbidity, and mortality were collected.

Preoperative investigations included complete blood picture, coagulation profile, liver and kidney function tests, tumor markers, ultrasonography, and CT (Fig. 1) 


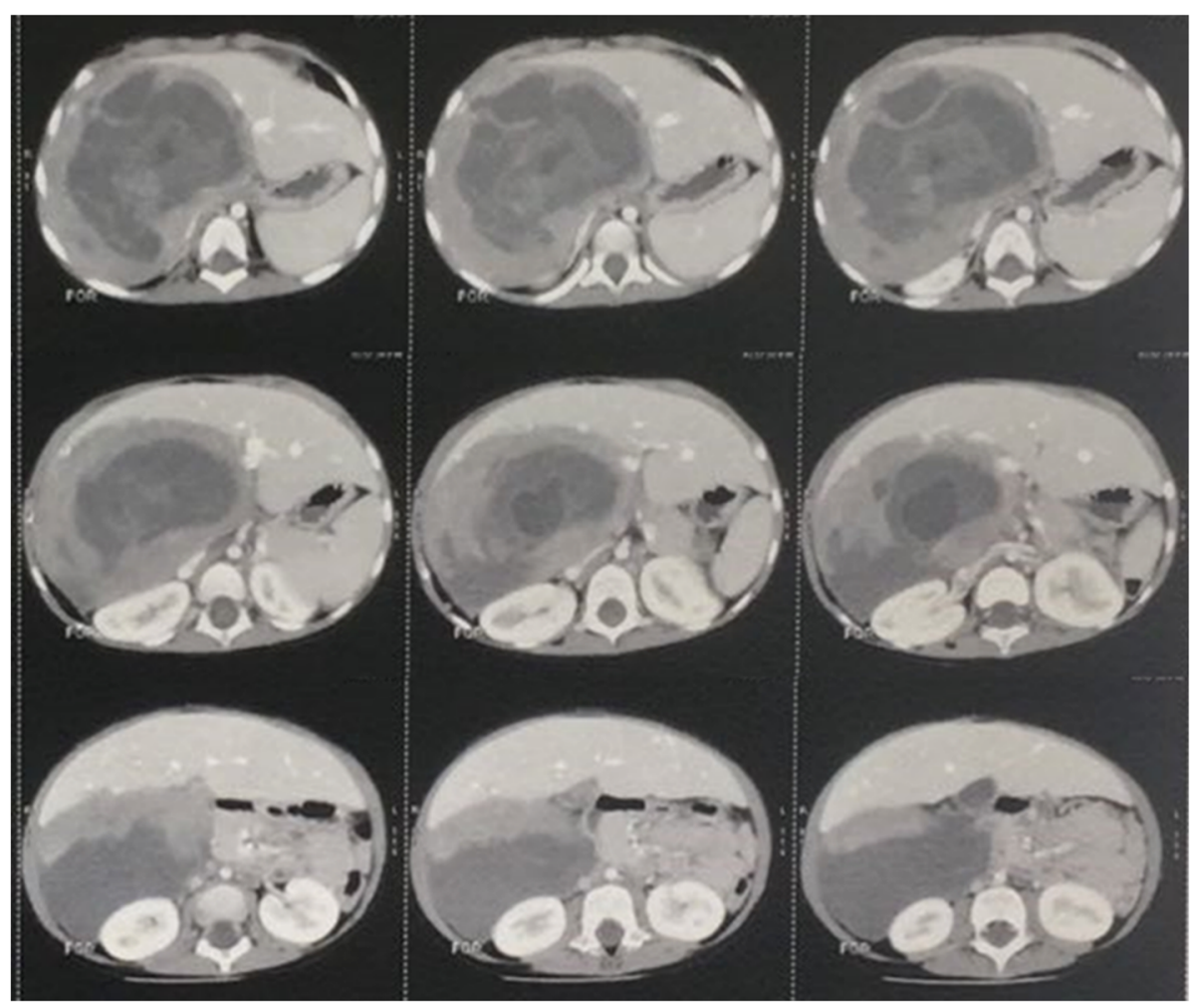

Fig. $1 \mathrm{CT}$ of right-sided mesenchymal hamartoma

with volumetry. Magnetic resonant cholangiography and $\mathrm{CT}$ angiography were reserved for selected cases.

\section{Operative technique}

Hepatectomies started by right subcostal incision with upper midline extension to the xiphoid process along with a left subcostal extension if necessary. The falciform, coronary, and triangular ligaments were divided to mobilize the liver and expose the suprahepatic vena cava. After cholecystectomy, careful hilar dissection was done to expose the portal vein below the triangle of Calot. Intraoperative ultrasonography was performed to delineate the extension of the mass and anatomy of liver vasculature. Courses of hepatic veins were marked on the liver surface by diathermy. Patients were prepared to perform Pringle's maneuver if needed through passing a tape in the foramen of Winslow and keeping it untied. Selective vascular occlusion of inflow and outflow vessels was done in all cases except those who presented with benign exophytic lesions where non-anatomical resection was the method used (Figs. 2 and 3). Harmonic scalpel was the energy device used for parenchymal resection. Argon beam coagulator was used to achieve hemostasis at the raw liver surface with application of fibrillar $^{\mathrm{rat}}$ when needed. We did not use any method to diagnose biliary leak initially; however, based on the high incidence of minor leak in our first 15 cases, we adopted

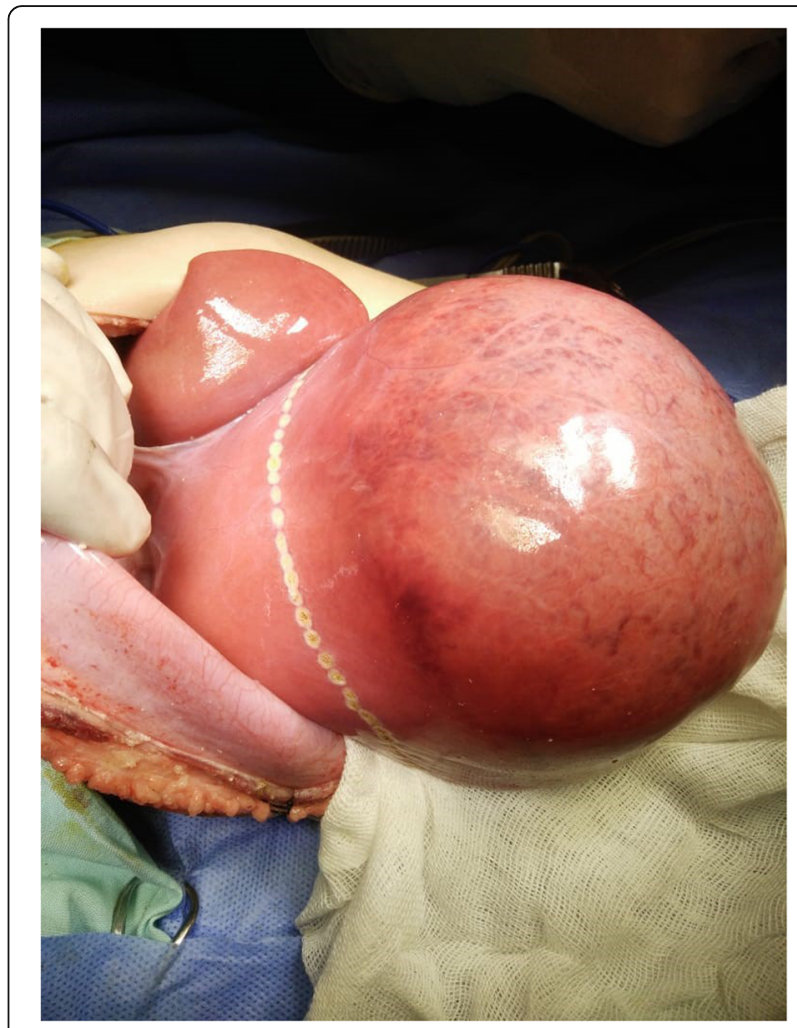

Fig. 2 Exophytic mesenchymal hamartoma, segments II and III 

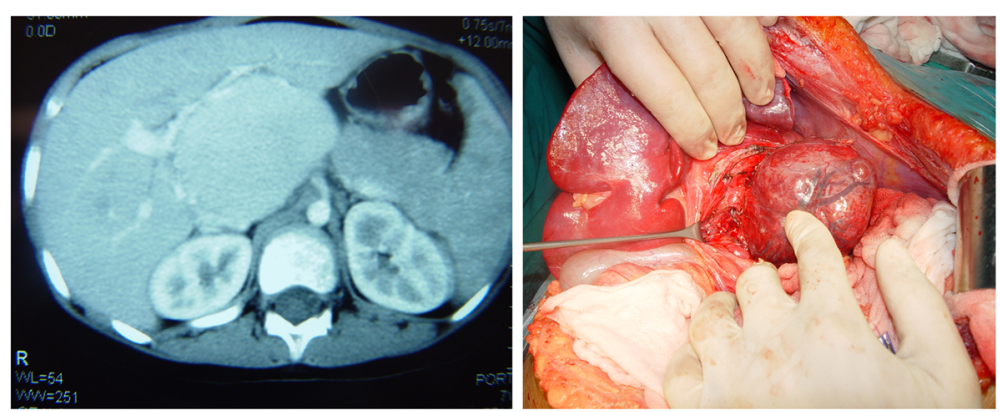

Fig. 3 Exophytic mesenchymal hamartoma, segment I

a routine saline test in our subsequent 12 cases which dramatically decreased leakage. A subphrenic drain was left. Starting from the fourth case onwards, the remaining liver was fixed to the anterior abdominal wall to avoid torsion.

After surgery, patients were transferred to the intensive care unit until stabilization of the general condition. Liver function tests were checked every other day. Feeding was initiated once bowels were open. Drain was removed once output became clear serous fluid and dropped below $50 \mathrm{ml}$ per day. Ultrasound and Doppler ultrasound were done before discharge to exclude any intraabdominal collection or biliary radical dilatation and to check adequacy of blood flow to the remaining liver respectively.

\section{Results}

This study included 27 patients who underwent different types of hepatectomies (Table 1). There was male predominance (16 males and 11 females). Age ranged from 6 months to 13 years (mean 3.88 years). Weight ranged from 5.7 to $33.7 \mathrm{~kg}$ (mean $15 \mathrm{~kg}$ ). A segment or more of the right lobe was affected in 15 cases. Indications for hepatectomies included hepatoblastoma in 10 cases (Fig. 4), 9 cases of mesenchymal hamartoma, HCC in 3 (Fig. 5), focal nodular hyperplasia in 3, and hemangioendothelioma in 2. Hepatitis $\mathrm{C}$ was positive in all cases presenting with HCC. Type of hepatectomies performed included right hepatectomy in 12 patients, extended right hepatectomy in 2, right posterior segmentectomy in 1 , left lateral segmentectomy in 6 , left hepatectomy in 3, and non-anatomical resections in 3 cases. Selective vascular occlusion was the vascular clamping technique used in all cases, which underwent anatomical resections. Non-anatomical resections were done in cases of exophytic mesenchymal hamartomas not warranting formal resections.

Total operative time ranged from 68 to $322 \mathrm{~min}$ (mean \pm standard deviation $173.7 \pm 65 \mathrm{~min}$ ), while resection time ranged from 34 to 144 min (mean \pm standard deviation $88.8 \pm 35.3 \mathrm{~min}$ ). Operative time was shorter in benign conditions and was directly related to the size of the mass. The mean resection time for malignant and benign lesions was $91.6 \mathrm{~min}$ and $86.1 \mathrm{~min}$ respectively. Blood loss ranged from 53 to $259 \mathrm{ml}$ (mean \pm standard deviation $119.3 \pm 51 \mathrm{ml}$ ). Only 5 patients required intraoperative blood transfusion. Resection of malignant lesions was associated with more blood loss. The mean blood loss for malignant lesions was $135.7 \mathrm{ml}$ and for benign lesions was $104 \mathrm{ml}$.

Surgical morbidities included five patients (18.5\%) with minor biliary leaks. They were managed conservatively with drainage and were followed up through clinical examination, laboratory data, and ultrasonographic scans to rule out the presence of intraperitoneal collection or biliary dilatation. Those patients were sent home once tolerating full oral feeds. Their drains were removed when output declined into nil, unlike other patients who had their drains removed when output became clear serous fluid and dropped below $50 \mathrm{ml}$ per day. Three patients (11.1\%) had a surgical site infection (SSI). They were managed by antibiotics and local wound control. One patient had torsion of the remnant liver necessitating repositioning. This case was manifested by deterioration in the level of consciousness. Liver enzymes were rising. Urgent Doppler ultrasound showed complete hepatic venous outflow obstruction with severe congestion of the remnant liver.

The follow-up period ranged from 6 to 54 months (median 25 months). Recurrence was encountered in three patients with hepatoblastoma 4, 6, and 12 months post-operatively. One had liver transplantation, while the other two had another successful resection.

We had two post-operative deaths. One of them occurred $2 \mathrm{~h}$ postoperative as a sequala of massive intraoperative bleeding from tumor rupture, while the other resulted from post-hepatectomy liver failure despite adequate remnant liver tissue as was shown by preoperative CT volumetry.

\section{Discussion}

The most life-threatening complication during liver resections is hemorrhage whether intraoperative or postoperative [4]. Unlike adults, children have small blood 


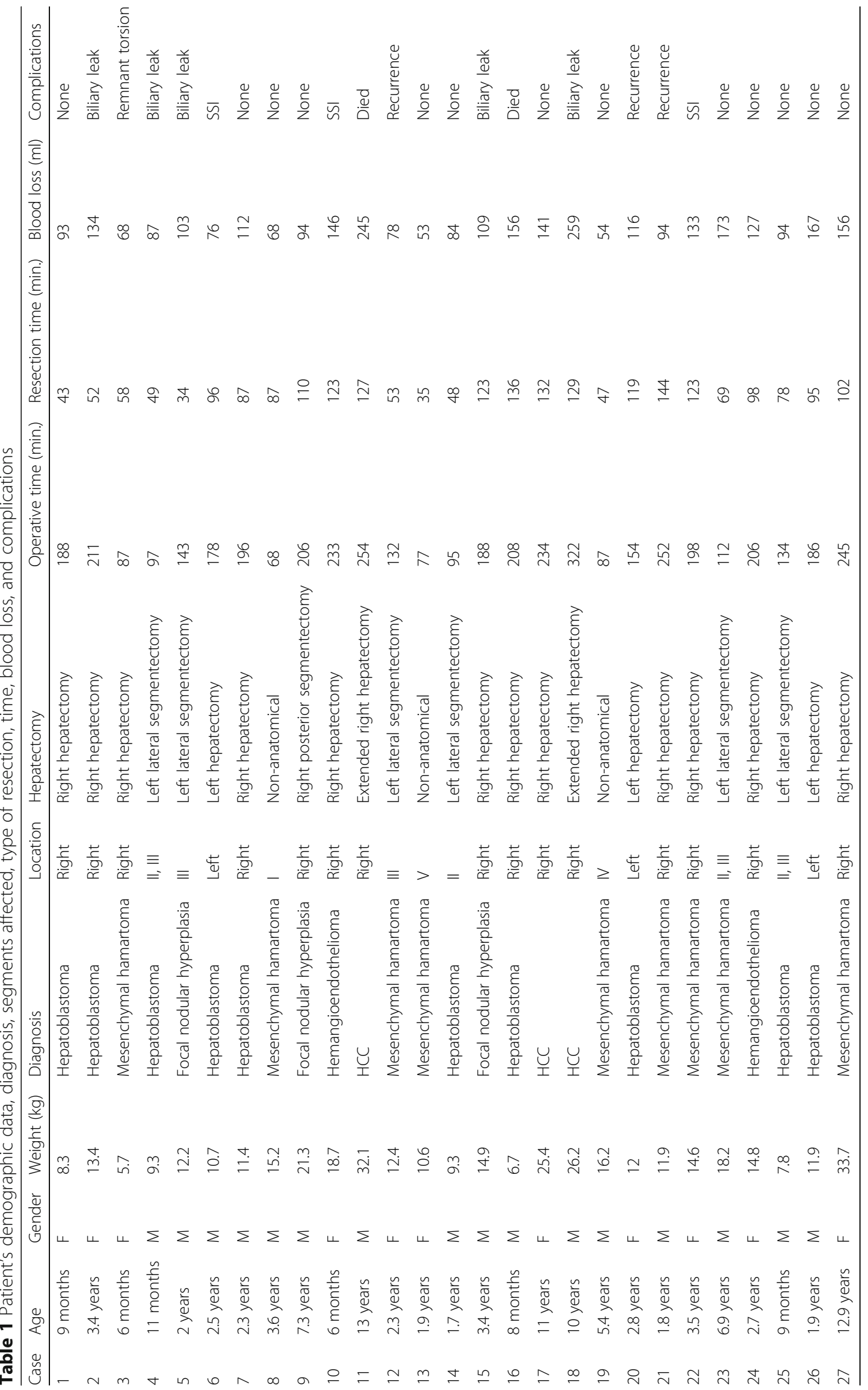




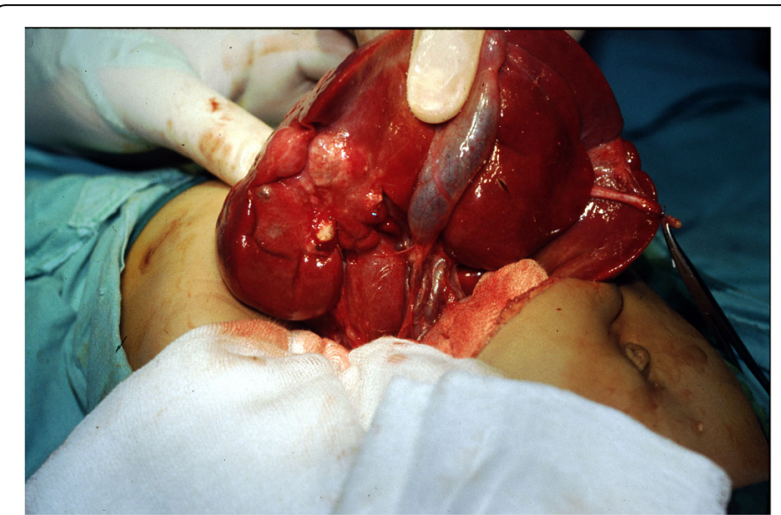

Fig. 4 Right-sided hepatoblastoma

volumes and can suffer greatly from blood loss as small as $100 \mathrm{ml}$. Furthermore, children have near-normal liver tissue leading to more hemorrhage when compared to cirrhotic adult liver [6]. Meticulous surgical techniques are crucial to minimize blood loss, particularly avoiding injury to the small tributaries draining into the inferior vena cava which should be ligated in continuity then cut, instead of cauterized, because they will bleed extensively if severed [4]. Wang and his colleagues suggested that maintaining a low central venous pressure $(2-4 \mathrm{mmHg}$ ) can reduce blood loss [7]. In our cases, we were keen to maintain central venous pressure below $5 \mathrm{cmH}_{2} \mathrm{O}$ to decrease bleeding and blood transfusion. If injury to one of the hepatic veins has occurred, the anesthesiologist deliberately increased the peak end expiratory pressure to guard against air embolism. The Society of Pediatric Oncology Liver Tumor Study Group launched its first prospective trial (SIOPEL-1) in 2002. Among the 100 patients who underwent hepatectomy, hemorrhage was less than $500 \mathrm{ml}$ in $60 \%$ of cases, while it was more than $1000 \mathrm{ml}$ in $13 \%$ of them [8]. In comparison, intraoperative blood loss was less than $500 \mathrm{ml}$ in all our cases. In a study published in 2017

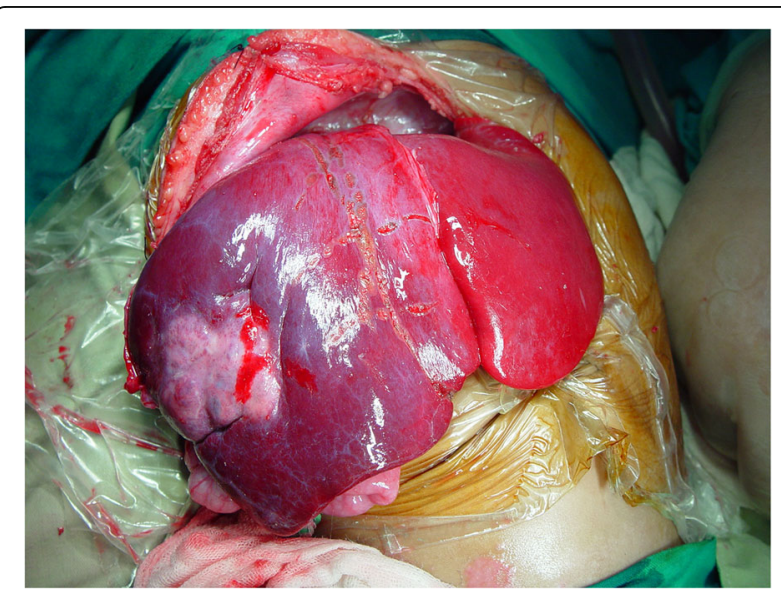

Fig. 5 Right-sided HCC
[9], Busweiler and his colleagues reported blood transfusion in $45 \%$ of 73 patients underwent partial hepatectomy. In our series, $18.5 \%$ of our patients received blood transfusion.

Many vascular clamping techniques are available in the surgeon's hands. Pringle's maneuver being the simplest and highly effective. However, ischemia of remaining liver and intestinal congestion always occur. Total vascular exclusion ensures a bloodless operation, but still has its drawbacks on hemodynamic stability. Makuuchi and his coworkers described selective vascular exclusion in 1987 obviating disadvantages of both Pringle's maneuver and total vascular exclusion [10]. Selective vascular occlusion together with high dissection of the porta hepatis and ligation of up to second-order branches of portal and arterial vessels were used in our series. This technique has been proved to be both effective and safe by many other authors [11]. It decreases visceral congestion as part of the portal flow is preserved, furthermore only the excised portion of the liver is subjected to anoxia [12].

Many methods are available for parenchymal resection such as finger fracture, clamp crushing, and different energy devices [13-15]. Among the variety of parenchymal resection methods enumerated, we opted for the use of harmonic scalpel. Harmonic scalpel causes protein denaturation and coagulation by high-frequency ultrasound vibration. Despite decreasing resection time and bleeding when compared to finger fracture, it was associated with a higher incidence of the biliary leak [16]. We did have 5 cases (18.5\%) with postoperative minor biliary leak in our series; however, all were treated conservatively.

Intraoperative ultrasonography was introduced in the 1980s [17]. Since then, intraoperative ultrasonography has been a very useful tool to define the extent of the mass and its relation to the important vascular structures. It can detect new tumors not diagnosed preoperatively or reveal new information about the lesion [18]. Several reports suggested a rate of $20 \%$ alteration in surgical plan due to information gained from intraoperative ultrasonography [19]. In our series, it changed our initial plan from right posterior hepatectomy to right hepatectomy in 2 cases $(7.4 \%)$ due to the detected change in tumor extent. Also, delineation of the main hepatic veins was of great help to decrease blood loss.

Biliary leak is not an uncommon complication after hepatectomies. Most are minor leaks from the resection margin, which resolve with expectant management. However, rare leaks from disconnected ducts or excluded segment duct may carry a grave prognosis [20]. Such major leaks are commonly caused by aberrant anatomy of biliary tree. Trans-cystic cholangiography using radio-opaque dye, methylene blue, indigo-carmine, fat emulsion, or normal saline is recommended by many authors to diagnose and suture any leak $[21,22]^{\cdot}$ We did not use any bile 
leakage test initially in the first 15 cases. We had a minor biliary leak in 4 cases (26.7\%). Therefore, we started to use saline test routinely. As a result, we had only 1 case of minor bile leak in our subsequent 12 cases. Yamashita and his coauthors reported incidence of $4.5 \%$ bile leak without leak test and $0 \%$ after they started testing with saline [23]. They concluded that saline test is safe and effective in reducing bile leak rates to $0 \%$.

A case with $\mathrm{HCC}$ and hepatitis $\mathrm{C}$ virus died due to hepatic insufficiency after extended right hepatectomy, although CT volumetry of this patient confirmed adequacy of remnant liver tissue. Inaccuracy in $\mathrm{CT}$ volumetry results may be attributed to the difference between radiological plane and actual surgical plane. Radtke and associates reported overestimation of volume in $61 \%$ of cases and underestimation in $15 \%$ due to extreme difficulty to follow Cantlie's line especially in two-dimensional images [24]. Furthermore, CT volumetry does not assess for the function in the remnant liver tissue; therefore, it is only accurate in patient with healthy parenchyma. Dinant and others reported $13 \%$ liver cell failure despite adequate remnant liver tissue calculated by volumetry. They concluded that hepatobiliary scintigraphy is more accurate in assessing adequacy of future remnant [25]. Also, the use of a fixed conversion factor when converting volume to weight is doubtful since there may be individual variation [26].

Although hepatic venous outflow obstruction due to torsion is a well-known life-threatening complication after liver transplantation, it has been reported sporadically in the literature in the remaining left lobe after right hepatectomy [27]. To the best of our knowledge, our case is the first to be reported in an infant. This case was early in our series. After which, we have started to routinely fix the remnant liver to the falciform ligament.

Despite advances in surgical techniques, liver resection remains a complex and high-risk procedure. There is limited data in the literature regarding perioperative and short-term outcome in pediatric population. The first prospective trial of The Society of Pediatric Oncology Liver Tumor Study Group (SIOPEL-1) reported 18\% surgical morbidity and 5\% surgical mortality [8]. In an attempt to define the short-term outcome in children, Zwintscher and his coauthors reviewed the database of 126 children who underwent liver resection in 2009 due to primary hepatic malignancy. They reported $30.7 \%$ morbidity and $3.7 \%$ mortality [28]. In 2016, a chart review was carried out to assess postoperative complications in children underwent partial hepatectomy for hepatoblastoma in the Netherlands between 1990 and 2013 [9]. Complications were found in $58 \%$ of 73 patients but there was no early mortality (within 30 days). In our series, there was an overall morbidity rate of $44.4 \%$, while the mortality rate was $7.4 \%$.
We had an $11.1 \%$ infection rate in the form of SSI, but there was no wound dehiscence or reoperation. Vascular complications occurred in $3.6 \%$ of our cases in the form of hepatic venous outflow obstruction in one case. In comparison, Busweiler and his colleagues reported $8 \%$ infection rate with reoperation on two occasions. Also, they reported vascular complications in 3\% of their cases in the form of Budd Chiari Syndrome in one patient and thrombosis of the portal and left hepatic veins in another case [9].

In adults, minimally invasive liver resection (MILR) is well established for resection of both benign and malignant tumors with comparable outcome to open resection $[29,30]$. Different techniques used included pure laparoscopy, hand-assisted laparoscopy, and the hybrid technique [31]. In children, literature and evidence are lacking to support MILR as most published articles are case reports and small case series [31,32], which can be explained by the rarity of cases and the limited peritoneal domain in children that hinders MILR. To the best of our knowledge, there is only one large retrospective study in the English literature published in 2016, which lacks comparison versus open technique [33]. We believe MILR in pediatric population requires specialized training to develop appropriate expertise, highly equipped theaters, and proper patient selection.

Limitations of our study included being a retrospective one, besides the absence of a control group.

\section{Conclusion}

For a safe hepatectomy to be carried out, thorough familiarity of the hepatic segmental anatomy together with the various techniques for parenchymal resection and vascular control are fundamental. Injection of saline to determine any biliary leak and fixation of the remnant liver to the anterior abdominal wall are simple steps, yet lower complication rate. Results of CT volumetry should be considered within the context of the global liver function.

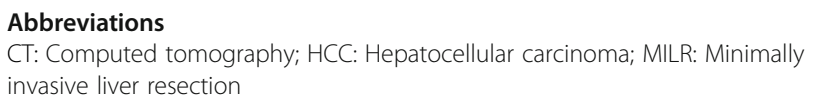

\section{Acknowledgements}

Not applicable.

\section{Authors' contributions}

HA, MA, MA, and AY contributed equally in the design of the work, collection and analysis of data, drafting and revising of the manuscript, and approving the final version for publishing.

\section{Funding}

Not applicable

\section{Availability of data and materials}

All data generated or analyzed during this study are included in this published article. 


\section{Ethics approval and consent to participate}

Ethical committee of the Surgery Department, Faculty of Medicine, Ain-Shams University approval was obtained in September 2018. Consent to participate is not applicable as our study is retrospective and descriptive not experimental.

\section{Consent for publication}

Not applicable as there is neither personal data nor images that will enable a patient to be identified.

\section{Competing interests}

The authors declare that they have no competing interests.

\section{Author details}

${ }^{1}$ Pediatric Surgery Department, Ain-Shams University, Abbaseya, Cairo, Egypt.

${ }^{2}$ Pediatric Surgery Department, Helwan University, Cairo, Egypt.

Received: 4 June 2019 Accepted: 2 September 2019

Published online: 01 October 2019

\section{References}

1. Chen WJ, Lee JC, Hung WT (1988) Primary malignant tumor of liver in infants and children in Taiwan. J Pediatr Surg. https://doi.org/10.1016/S00223468(88)80448-2

2. Ni Y-H, Chang M-H, Hsu H-Y et al (1991) Hepatocellular carcinoma in childhood. Clinical manifestations and prognosis. Cancer. https://doi.org/10. 1002/1097-0142(19911015)68:8<1737::AID-CNCR2820680815>3.0.CO;2-G

3. Perilongo G, Shafford EA (1999) Liver tumours. Eur J Cancer. https://doi.org/ 10.1016/S0959-8049(99)00049-0

4. Lin CC, Chen CL, Cheng YF, Chiu KW, Jawan B, Hsaio CC (2006) Major hepatectomy in children: Approaching blood transfusion-free. World J Surg. https://doi.org/10.1007/s00268-005-0607-7

5. Millat B, Hay JM, Descottes B, Fingerhut A, Fagniez PL, Fingerhut A (1992) Prospective evaluation of ultrasonic surgical dissectors in hepatic resection: a cooperative multicenter study. HPB Surg. https://doi.org/10.1155/1992/59508

6. Stringer MD, Hennayake S, Howard ER et al (1995) Improved outcome for children with hepatoblastoma. Br J Surg. https://doi.org/10.1002/bjs.1800820334

7. Wang WD, Liang LJ, Huang XQ, Yin XY (2006) Low central venous pressure reduces blood loss in hepatectomy. World J Gastroenterol. https://doi.org/ 10.3748/wjg.v12.i6.935

8. Schnater JM, Aronson DC, Plaschkes J et al (2002) Surgical view of the treatment of patients with hepatoblastoma: Results from the first prospective trial of the International Society of Pediatric Oncology Liver Tumor Study Group (SIOPEL-1). Cancer. https://doi.org/10.1002/cncr.10282

9. Busweiler LAD, Wijnen MHWA, Wilde JCH et al (2017) Surgical treatment of childhood hepatoblastoma in the Netherlands (1990-2013). Pediatr Surg Int https://doi.org/10.1007/s00383-016-3989-8

10. Makuuchi M, Mori T, Gunven P, Yamazaki S, Hasegawa H (1987) Safety of hemihepatic vascular occlusion during resection of the liver. Surg Gynecol Obs. 164(2):155-158

11. Li M, Zhang C, Zhang T et al (2015) Outcome using selective hemihepatic vascular occlusion and Pringle maneuver for hepatic resection of liver cavernous hemangioma. World J Surg Oncol. https://doi.org/10.1186/ s12957-015-0680-9

12. Chouillard EK, Gumbs AA, Cherqui D (2010) Vascular clamping in liver surgery: physiology, indications and techniques. Ann Surg Innov Res. https://doi.org/10.1186/1750-1164-4-2

13. Lin TY (1974) A simplified technique for hepatic resection: the crush method. Ann Surg. https://doi.org/10.1097/00000658-197409000-00005

14. Belghiti J, Hiramatsu K, Benoist S, Massault PP, Sauvanet A, Farges O (2000) Seven hundred forty-seven hepatectomies in the 1990s: an update to evaluate the actual risk of liver resection. J Am Coll Surg. https://doi.org/10 1016/S1072-7515(00)00261-1

15. Imamura H, Seyama $Y$, Kokudo $N$ et al (2003) One thousand fifty- six hepatectomies without mortality in 8 years. Arch Surg. https://doi.org/10. 1001/archsurg.138.11.1198

16. Kim J, Ahmad SA, Lowy AM et al (2003) Increased biliary fistulas after liver resection with the harmonic scalpel. Am Surg 69(9):815-819

17. Makuuchi M, Hasegawa H, Yamazaki S, Takayasu K, Moriyama N (1987) The use of operative ultrasound as an aid to liver resection in patients with hepatocellular carcinoma. World J Surg. https://doi.org/10.1007/BF01655837
18. Van Vledder MG, Pawlik TM, Munireddy S, Hamper U, De Jong MC, Choti MA (2010) Factors determining the sensitivity of intraoperative ultrasonography in detecting colorectal liver metastases in the modern era. Ann Surg Oncol. https://doi.org/10.1245/s10434-010-1108-y

19. Jrearz R, HartMD R, Jayaraman S (2015) Intraoperative ultrasonography and surgical strategy in hepatic resection: What difference does it make? Can J Surg. https://doi.org/10.1503/cjs.016914

20. Kapoor S, Nundy S (2012) Bile duct leaks from the intrahepatic biliary tree: a review of its etiology, incidence, and management. HPB Surg. https://doi. org/10.1155/2012/752932

21. Kaibori M, Matsui K, Ishizaki M, lida H, Kon M (2016) Intraoperative indocyanine green fluorescent imaging for prevention of bile leakage after hepatic resection. In: ICG Fluorescence Imaging and Navigation Surgery. https://doi.org/10.1007/978-4-431-55528-5_35

22. Sakaguchi T, Suzuki A, Unno N et al (2010) Bile leak test by indocyanine green fluorescence images after hepatectomy. Am J Surg. https://doi.org/ 10.1016/j.amjsurg.2009.10.015

23. Yamashita Yl, Hamatsu T, Rikimaru T et al (2001) Bile leakage after hepatic resection. Ann Surg. https://doi.org/10.1097/00000658-200101000-00008

24. D'Onofrio M (2014) Liver volumetry: Is imaging reliable? Personal experience and review of the literature. World J Radiol. https://doi.org/10.4329/wjr.v6.i4.62

25. Dinant S, de Graaf W, Verwer BJ et al (2007) Risk assessment of posthepatectomy liver failure using hepatobiliary scintigraphy and $\mathrm{CT}$ volumetry. J Nucl Med. https://doi.org/10.2967/jnumed.106.038430

26. Hwang S, Lee SG, Kim KH et al (2002) Correlation of blood-free graft weight and volumetric graft volume by an analysis of blood content in living donor liver grafts. Transplant Proc. https://doi.org/10.1016/S00411345(02)03603-5

27. Wang JK, Truty MJ, Donohue JH (2010) Remnant torsion causing buddchiari syndrome after right hepatectomy. J Gastrointest Surg. https://doi. org/10.1007/s11605-009-1148-4

28. Zwintscher NP, Azarow KS, Horton JD (2014) Morbidity and mortality associated with liver resections for primary malignancies in children. Pediatr Surg Int. https://doi.org/10.1007/s00383-014-3492-z

29. Koffron AJ, Auffenberg G, Kung R, Abecassis M (2007) Evaluation of 300 minimally invasive liver resections at a single institution: less is more. Ann Surg. https://doi.org/10.1097/SLA.0b013e318146996c

30. Han HS, Shehta A, Ahn S, Yoon YS, Cho JY, Choi Y (2015) Laparoscopic versus open liver resection for hepatocellular carcinoma: Case-matched study with propensity score matching. J Hepatol. https://doi.org/10.1016/j. jhep.2015.04.005

31. Dutta S, Nehra D, Woo R, Cohen I (2007) Laparoscopic resection of a benign liver tumor in a child. J Pediatr Surg. https://doi.org/10.1016/j.jpedsurg.2007.01.045

32. Yoon YS, Han HS, Choi YS et al (2006) Total laparoscopic left lateral sectionectomy performed in a child with benign liver mass. J Pediatr Surg. https://doi.org/10.1016/j.jpedsurg.2005.10.068

33. Veenstra MA, Koffron AJ (2016) Minimally-invasive liver resection in pediatric patients: Initial experience and outcomes. HPB. https://doi.org/10.1016/j.hpb. 2015.11.004

\section{Publisher's Note}

Springer Nature remains neutral with regard to jurisdictional claims in published maps and institutional affiliations.

\section{Submit your manuscript to a SpringerOpen ${ }^{\circ}$ journal and benefit from:}

- Convenient online submission

- Rigorous peer review

- Open access: articles freely available online

- High visibility within the field

Retaining the copyright to your article

Submit your next manuscript at $>$ springeropen.com 